Article

\title{
Integrated Assessment of the Water, Sanitation and Hygiene Situation in Haitian Schools in the Time of Emergency
}

\section{Daniela Giardina *, Fausta Prandini and Sabrina Sorlini}

CeTAmb, Research Centre on Appropriate Technologies for Environmental Management in Developing Countries, Faculty of Engineering, University of Brescia, Via Branze 43-25123 Brescia, Italy; E-Mails: fausta.prandini@unibs.it (F.P.); sabrina.sorlini@unibs.it (S.S.)

* Author to whom correspondence should be addressed; E-Mail: dggiardina@yahoo.it; Tel.: + 92-342-226-6664.

Received: 25 June 2013; in revised form: 30 July 2013 / Accepted: 22 August 2013 / Published: 29 August 2013

\begin{abstract}
This study examines the water, sanitation and hygiene situation in 42 schools in Haiti after the earthquake of January 12, 2010, by using a comprehensive approach, which includes participatory assessment tools and formal surveys. By conducting a detailed assessment of school water and sanitation infrastructure conditions and of the perceptions of students and professors, a series of recommendations are provided to support further project implementation towards more sustainable results. Direct observations showed that schools lack safe drinking water, appropriate sanitation and hand washing facilities. The main constraints to improve the water, sanitation and hygiene services were found to be related to lack of funding and infrastructure losses after the earthquake. Moreover, hygiene education is commonly not part of the school curriculum. Providing schools with adequate access to water and sanitation facilities and supporting the implementation of hygiene promotion programs, including a disaster risk preparedness plan, can play significant roles for a sustainable recovery phase.
\end{abstract}

Keywords: earthquake; emergency response; Knowledge; Attitudes and Practices (KAP) assessment; hygiene; schools; education; Haiti 


\section{Introduction}

Providing schools with appropriate water and sanitation facilities has been declared as one of the Target of the Goal 6, Post 2015 Millennium Development Goals (MDG) Discussion [1]. Having access to water and sanitation for children at school is a developmental goal, but also a key sector to support in times of disaster-related emergency. According to the Inter-Agency Network for Education in Emergencies [2], which set minimum standards for education, Standard 3 refers to the provision of basic services in schools as a child's right. Safe learning spaces should have the following: adequate sanitary facilities, taking into account age, gender and access for persons with disabilities; access to adequate quantities of safe drinking water and water for personal hygiene; and basic health and hygiene promotion in the learning environment. The basic services mentioned above are included in the broader SPHERE (Humanitarian Charter and minimum standards in disaster response), which is currently the most widely used reference manual for humanitarian response [3].

Ensuring that every school provides access to water, sanitation and hygiene for every child can be a huge challenge, especially after a disaster. When disaster strikes, education is often disrupted: schools become shelters for large numbers of displaced people, putting additional pressure on physically damaged buildings and facilities, and students are often excluded from a safe access to their school environment [4].

Haiti suffered a number of natural disasters, the most deadly of which was the earthquake on 12 January 2010, which caused the death of over 230,000 people and the displacement of about 1.5 million people [5]. Prior to the earthquake, $55 \%$ of Haitian children of primary school age did not attend school and, in the first aftermath of the disaster, the situation deteriorated, while after an increase in school attendance by $22 \%$ was registered [6]. In the West Department, the worst affected by the earthquake, almost $85 \%$ of the kindergarten, primary and secondary schools operational before the earthquake had been damaged or destroyed [7]. Since the earthquake devastated Haiti, schools have been struggling to resume their normal activities, starting to recommence as late as April, 2010.

Moreover, in light of many schools not meeting water and sanitation service provisions, schools have been facing major challenges from the threat of cholera, which started spreading throughout the country since October, 2010. Up to July 2013, cholera has caused 8197 deaths and 668,270 persons to be hospitalized [8]; the largest numbers of cases were of school-going age.

Since no comprehensive information was available on the specific status of water, sanitation and waste facilities, as well as hygiene promotion activities in Haitian schools, the main objectives of the study were (i) to carry out an integrated assessment of 42 schools in the West Department and (ii) to provide some suggestions from a programmatic point of view for a more sustainable recovery phase.

\section{Study Area}

The assessment conducted entailed the survey of 42 schools, 29 in Petit-Goâve and 13 in Grand-Goâve situated in the West Department of Haiti, the most severely affected by the earthquake. The mentioned schools were targeted for a project of the Italian Non-Governmental Organization for Cooperation and Development (CESVI) funded by the United Nations Children's Fund (UNICEF), Humanitarian Aid and Civil Protection department of the European Commission (ECHO) and the Italian Agency for 
Emergency Response (AGIRE). The main aim of the project was to create a healthy and safe learning environment for children in the 42 schools. Main activities of CESVI project were to build toilets and urinals, to improve water supply services and to install hand-washing facilities in the proximity of toilets according to the different needs of the schools. Moreover, as software component, CESVI staff carried out hygiene promotion campaigns in all 42 project schools.

The field study related to this paper was carried out between October 30, 2010 and December 3, 2010 with the aim to develop an integrated assessment of the water, sanitation and hygiene situation for the selected schools. The results of this field study are presented in this paper. The schools analyzed by the study are reported in a map (Figure 1) and the list of the analyzed schools is included in Appendix 1.

Figure 1. Location of 42 project schools (West Department, Haiti).

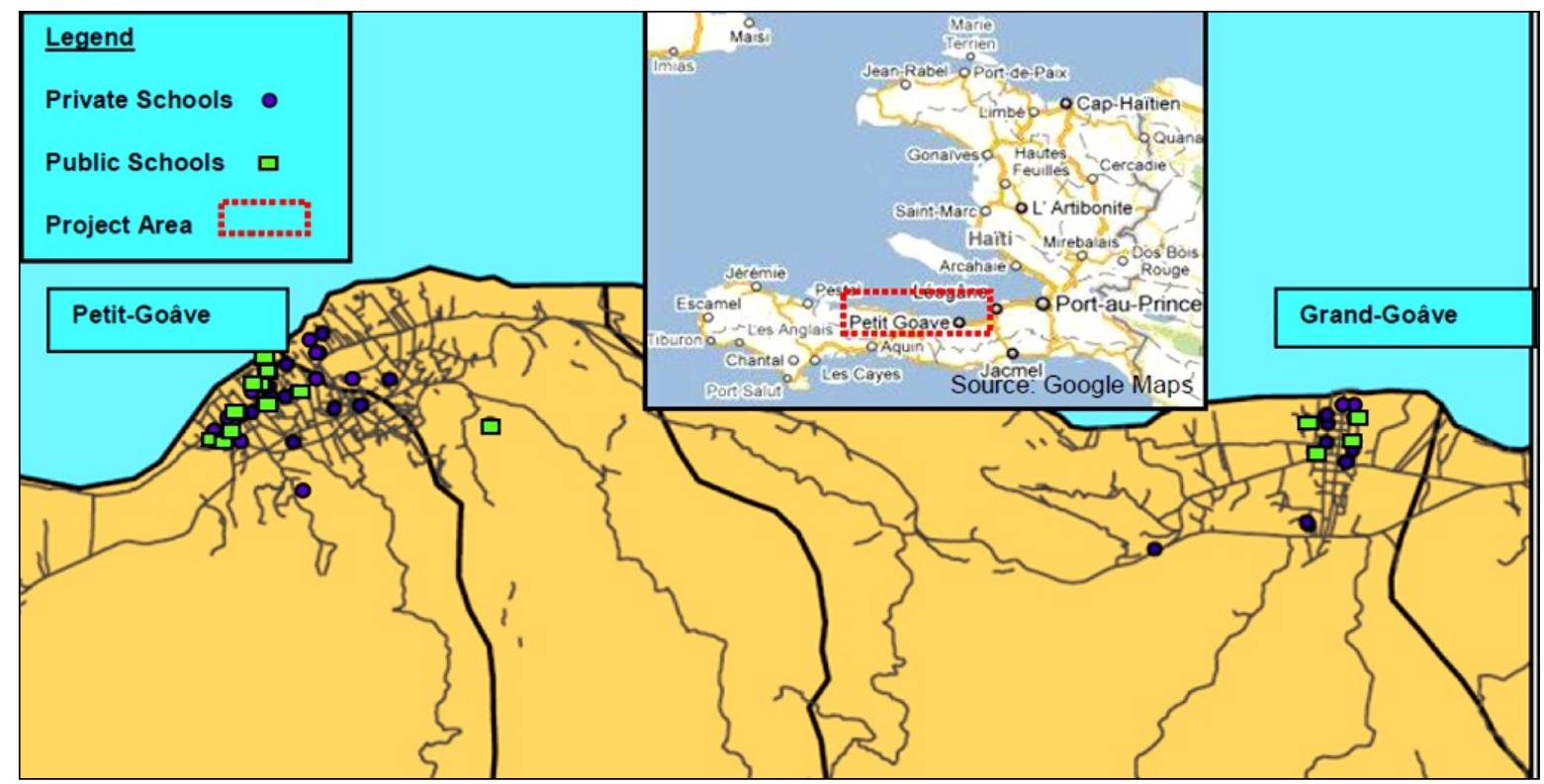

\section{Methods}

Both quantitative and qualitative, methods for data collection were chosen in order to gain relevant information and produce an integrated assessment. The qualitative approach was seen as appropriate since it helped to include the dimension of social and cultural relations and organizational structures $[9,10]$. The observational survey and the questionnaires were useful for the quantitative analysis and in order to get real and timely snapshot of the situation. In Table 1, a list of the methods that were used to collect and analyze data is reported.

\subsection{Selection and Training of Surveyors}

Surveys at the 42 schools were conducted by two male and four female surveyors who were trained during a week by the author to conduct Knowledge, Attitudes and Practices (KAP) surveys as well as semi-structured interviews and to undertake systematic observations of water and sanitation facilities in the sample schools. Three teams, consisting of two people each, undertook field surveys and administered the questionnaires at the schools. 


\subsection{Desk Study/Literature Review}

All data collected at field level was revised using relevant literature on Water, Sanitation and Hygiene (WASH) in schools and the available support data, reports and guidelines from the Education Cluster and the WASH cluster in Haiti. Not much information was available on the schools' situation in Haiti prior to the earthquake, and mostly information referred to the capital city Port-au-Prince. The Education Cluster set up the minimum requirements for water and sanitation facilities in schools as reported in the Discussion section, but the majority of the assessments available were carried out by individual institutions/UN agencies/NGO working on specific projects, mostly on Internally Displaced People's (IDP's) camps, thus resulting in scattered and fragmented data regarding schools.

Table 1. Data Collection \& Analysis Methods.

\begin{tabular}{|c|c|c|}
\hline Methods & Data Collected & Data Analysis \\
\hline Literature review & $\begin{array}{l}\text { Existing WASH in school } \\
\text { emergency information. } \\
\text { - Data on school situation in Haiti } \\
\text { before earthquake. } \\
\text { - Education/WASH cluster reports. } \\
\text { - Data on Haitian schools. }\end{array}$ & $\begin{array}{l}\text { Information on assessment usually } \\
\text { used in emergency response to } \\
\text { prepare surveys tables. } \\
\text { - Analysis and framing of the } \\
\text { intervention within the existing policy } \\
\text { requirements. }\end{array}$ \\
\hline $\begin{array}{l}\text { Infrastructural } \\
\text { Survey/direct } \\
\text { observation } \\
\text { (42 schools) }\end{array}$ & $\begin{array}{ll}\text { - } & \text { School building status } \\
\text { - } & \text { Water access } \\
\text { - } & \text { Sanitation access/ facilities } \\
\text { - } & \text { Solid Waste Management } \\
\text { - } & \text { School Fees } \\
\end{array}$ & $\begin{array}{l}\text { - Reported by the surveyors in a table } \\
\text { format } \\
\text { - Analyzed in Excel, with frequencies } \\
\text { and distribution. }\end{array}$ \\
\hline $\begin{array}{l}\text { Key informants/ semi } \\
\text { structured interview } \\
(42 \text { schools })\end{array}$ & $\begin{array}{l}\text { Strengths, Weaknesses, Opportunities } \\
\text { and threats for schools in terms of } \\
\text { water and sanitation services }\end{array}$ & $\begin{array}{l}\text { Strength, Weakness, Opportunity, } \\
\text { Threat (SWOT) analysis (Table 6) of } \\
\text { primary stakeholders involved in } \\
\text { WASH in schools. }\end{array}$ \\
\hline $\begin{array}{l}\text { Knowledge, Attitudes } \\
\text { and Practices (KAP) } \\
\text { questionnaires } \\
\text { ( } 21 \text { schools) }\end{array}$ & $\begin{array}{l}\text { - } 21 \text { schools: } \\
\text { General information about their } \\
\text { socio-economic status, their knowledge } \\
\text { about sanitation and water quality; their } \\
\text { attitude towards hygiene and their } \\
\text { common practices. }\end{array}$ & $\begin{array}{ll}\text { - } & \text { Data entered in Excel, Coding responses } \\
\text { - } & \text { EPINFO software } \\
\text { - } & \text { Frequencies, Simple correlation } \\
\text { - } & \text { Logistic regression (one variable) } \\
\text { - } & \text { Hygiene knowledge correlation with } \\
& \text { housing (poverty proxy) and gender. } \\
\end{array}$ \\
\hline
\end{tabular}

\subsection{Infrastructural Survey}

An infrastructural survey was carried out at the 42 project schools in order to evaluate what type of water and sanitation facilities were available and what their condition was. To perform this task a table was developed adapting different assessment tools available in the literature $[11,12]$. The survey table was filled in by trained surveyors through direct observations at the 42 CESVI project schools. The observations allowed the surveyors to inspect the state of school latrines, solid waste dumps and drinking water supply used at the school level. The results of the survey were entered in Excel and analyzed in terms of frequencies (Table 4). 


\subsection{Semi-Structured Interviews}

Semi-structured interviews were conducted by the trained surveyors with school directors and teachers in all the 42 schools. School directors were asked to highlight major challenges related to the water and sanitation infrastructures of their schools. In order to highlight the possibility of success and failure, a Strength, Weakness, Opportunity, Threat (SWOT) analysis was developed, based on the finding of the interviews, for primary stakeholders (school personnel, students, and local community) to identify the key internal (strengths and weaknesses) and external factors (opportunities and threats) that are important for the successful provisions of these services at school level.

\subsection{Knowledge, Attitudes and Practices (KAP) Questionnaire}

To provide a baseline of the existing knowledge, attitudes and practices (KAP) in drinking water, sanitation and hygiene, questionnaires were collected.

Knowledge refers to the interviewee's understanding of hygiene (further defined later), attitude refers to their feelings towards hygiene, as well as any preconceived ideas that they may have, and practice refers to the ways in which they demonstrate their knowledge and attitudes through their actions.

Three different types of questionnaires were developed: One format for primary school children, one for secondary school children and a third one for teachers and professors. The questionnaires were adapted to local practices by a review process implemented through a focus group discussion with the hygiene promoter's team, and the questionnaire was also tested in one school before starting the actual data collection. Few changes were made to the questionnaire for secondary school students after the trial of the questionnaire, while major changes were made to simplify the primary school questionnaire. Specific questions regarding cholera and the transmission routes were included in the questionnaires due to the contingency of the cholera emergency, and in light of the sensitization and prevention trainings conducted by CESVI at the 42 project schools. Questions regarding hygiene training for children were included specifically for teachers and professors. In Appendix 2, the titles of questionnaire sections are reported.

Since carrying out the questionnaires in all 42 schools of the project was unfeasible for time and security reasons, a sample selection was carried out using multi-stage sampling, as outlined in Figure 2. For the KAP questionnaires, out of the 42 schools, 21 schools were selected representing $50 \%$ of the project schools. A proportion between private schools and public schools was respected while selecting the sample.

It was unfeasible to interview the same number of students in each school due to different enrollment numbers, thus a sample varying from 15 up to a maximum of 33 students from different classes at secondary level was selected to undertake the questionnaires. The same was done for primary school students who were selected to be no younger than eight years of age.

As regards to the data analysis for the KAP, a coding system for data entry was developed and five of the hygiene promoters were trained in answer coding. The data entry was conducted using Excel spreadsheets, and a statistical analysis of the results was developed using EPI INFO software (Version 3.3.5), a public access software package made available by the United States Center for Disease Control and Prevention (CDC). Frequency was used for general characteristics descriptions, 
for infrastructural access and for preferences. Simple correlation was initially performed, with no statistically significant results. Odds Ratios (OR) and 95\% Confidence Intervals (CI) were calculated by logistic regression in order to determine the association of adequate knowledge of proper hygiene with gender (female as reference), and type of housing. Adequate knowledge was defined using the reply to the question: Do you know how to avoid diarrhea? (i) Washing hands with soap, (ii) using potable water, (iii) washing and cooking food well, (iiii) I don't know. If they replied yes to at least two options, the knowledge was defined as adequate.

Figure 2. Knowledge, Attitudes and Practices (KAP) schools' sample selection process.

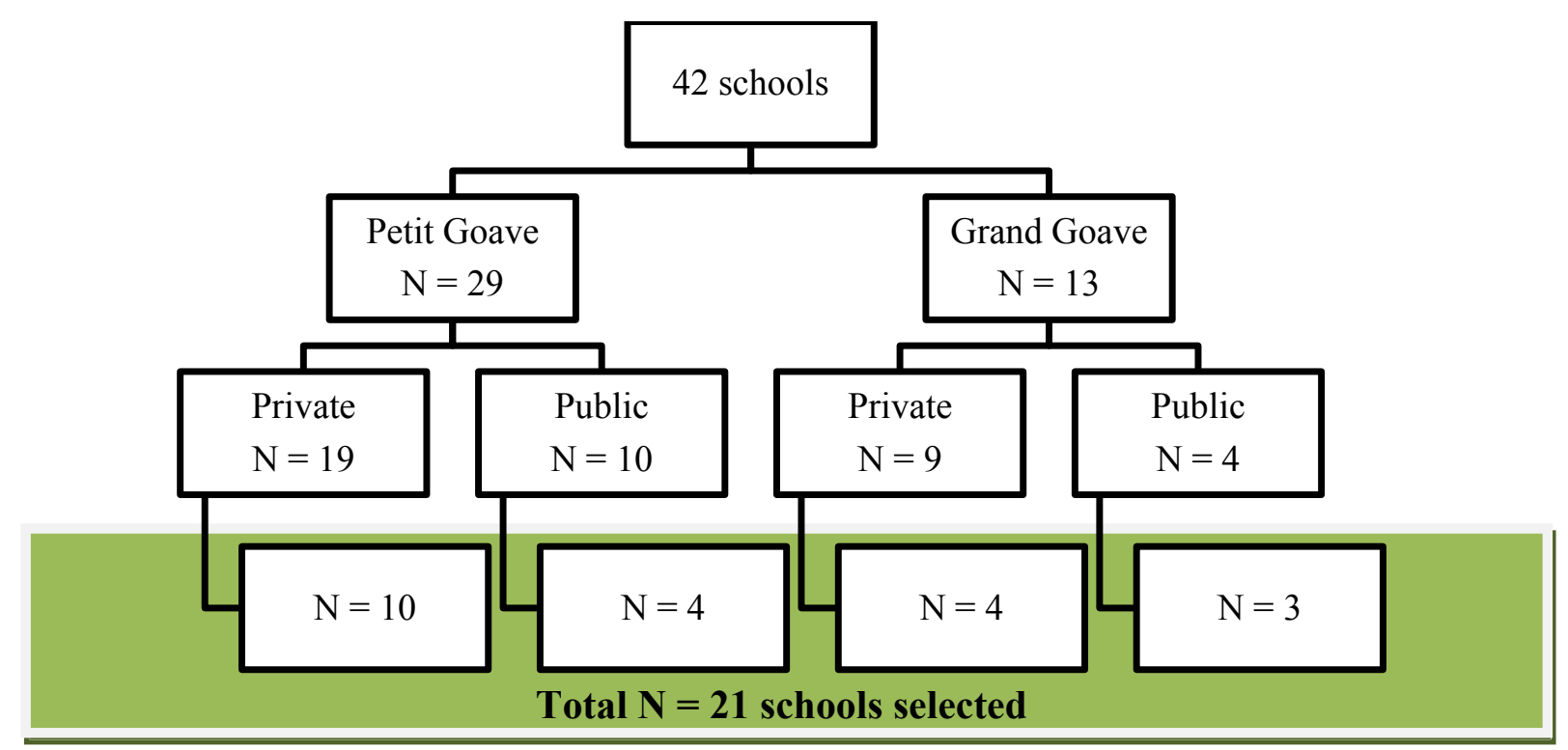

\subsection{Ethical Discussion}

Directors of the project schools were initially approached to explain the purpose of the survey and to ask for their consent. A letter of informed consent was drafted and signed by the school directors to give the permission to undertake the survey and to collect questionnaires from school children, teachers and professors. Prior to starting the questionnaire session, the trained surveyors explained the purpose and the anonymous way in which data would be handled.

\section{Results}

\subsection{Access to School Education}

The total number of schools operational before the earthquake was 269 in Petit-Goâve and 69 in Grand-Goâve [13]: The analysis entailed the survey of 42 schools representing the $12.4 \%$ in that area. Out of the 42 project schools in Petit-Goâve and Grand-Goâve, 67\% are private and 33\% are public. This trend is expected throughout Haiti, where the vast majority of schools were private before the earthquake and in the absence of a well-developed and functioning system of public schools [14]. Private-run schools have been largely operating without regulation and below minimum standards, not using approved curricula by the Ministry of Education [14]. Private run schools often do not comply with basic requirements in terms of respecting approved national curricula and the training of teachers, 
since they are often set up by an individual or the community for the lack of public schools in a specific area. School fees for public schools were a minimum of 100 HTG (Haitian currency Gourdes) per student per year (approximately 2.48 USD); sixty percent of the fees were transferred to the Ministry of Education, the rest used for operational cost of the establishments. Some public schools have increased the yearly fee in order to be able to pay teachers and professors who are not nominated by the public system, but necessary in order to conduct teaching activities at the school. Private school fees varied greatly also based on the school level (primary or secondary school). The average per capita income in Haiti is 653.7 USD/per capita/year [15] and based on the data collected, school fees can be a large percentage of the yearly average per capita income, varying from $0.4 \%$ for public schools, up to as high as $57 \%$ for private schools as shown in Table 2 .

Table 2. Private and public project schools characteristics (Source: Author).

\begin{tabular}{c|c|c|c|c|c|c}
\hline $\begin{array}{c}\text { School } \\
\text { type }\end{array}$ & $\begin{array}{c}\text { Number of } \\
\text { project schools } \\
\mathbf{n = 4 2} \mathbf{( \% )}\end{array}$ & $\begin{array}{c}\text { Average number of } \\
\text { children per } \\
\text { teacher }\end{array}$ & $\begin{array}{c}\text { Yearly } \\
\text { school fees } \\
\text { (HTG) }\end{array}$ & $\begin{array}{c}\text { Yearly } \\
\text { school fees } \\
\text { (USD) }\end{array}$ & $\begin{array}{c}\text { Mean } \\
\text { (Median) } \\
\text { (USD) }\end{array}$ & $\begin{array}{c}\text { \% on yearly } \\
\text { average income }\end{array}$ \\
\hline Public & $14(67)$ & 54 & $100-500$ & $2.48-12.42$ & $3.41(6.92)$ & $0.4-2$ \\
\hline Private & $28(33)$ & 20 & $1000-15000$ & $24.84-372.67$ & $138.5(196.19)$ & $4-57$ \\
\hline
\end{tabular}

\subsection{Results of the KAP Questionnaires and Infrastructural Survey in Petit-Goâve and Grand-Goâve}

The KAP questionnaires were administrated and collected from 21 schools (Table 2). A total of 358 KAP questionnaires were collected from primary school children, while 573 were collected from secondary school students, and 177 from teachers and professors, as shown in Figure 3. Pupils filling in the questionnaire were from different classes and grades, as reported in Table 3. A higher percentage of questionnaires from students and teachers/professors were collected in Petit-Goâve (76\% primary school, 75\% secondary school and 77\% teachers), compared to Grand-Goâve (26\% primary schools, $25 \%$ secondary school, $23 \%$ teachers).

Figure 3. Flow Chart of KAP Questionnaires Collected from Students.

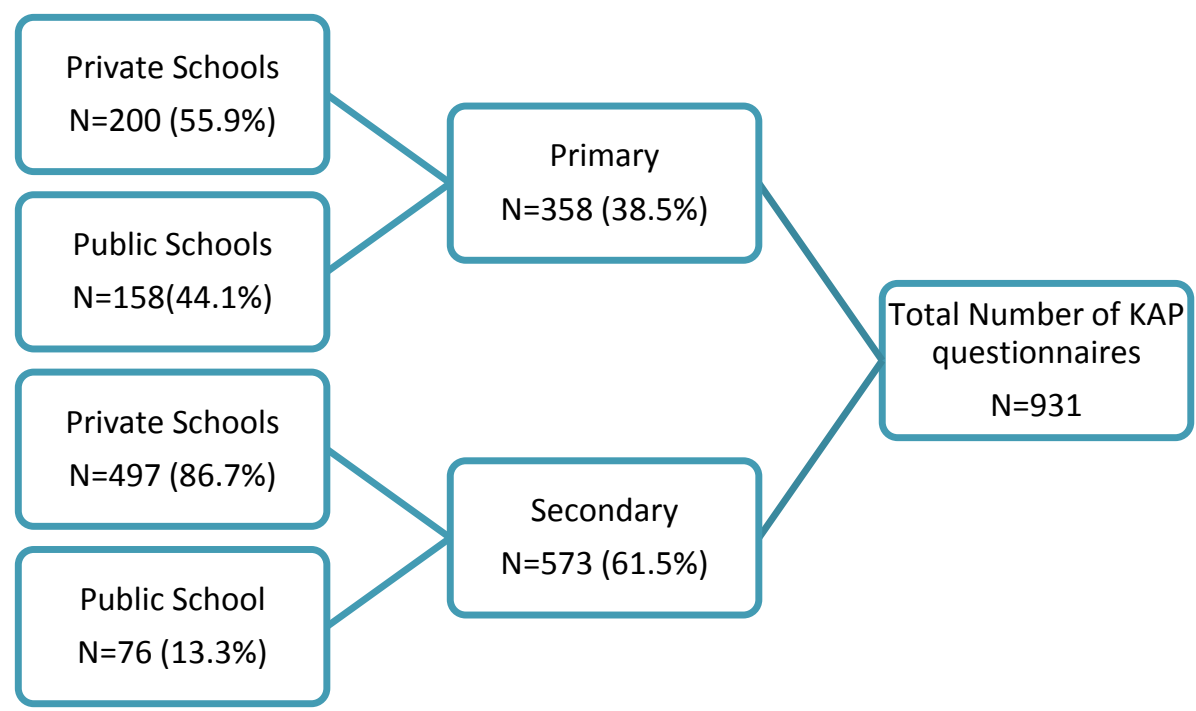


Table 3. General characteristics of primary and secondary school's pupils. (Source: Author).

\begin{tabular}{|c|c|c|c|c|c|c|}
\hline \multirow[t]{2}{*}{ Characteristic } & \multicolumn{3}{|c|}{ Primary School Pupils } & \multicolumn{3}{|c|}{ Secondary School Students } \\
\hline & Responses & $(\mathrm{N}=358)$ & $\%$ & Responses & $(\mathrm{N}=573)$ & $\%$ \\
\hline \multirow{2}{*}{ Town } & Grand-Goâve & 94 & 26 & Grand-Goâve & 144 & 25 \\
\hline & Petit-Goâve & 264 & 74 & Petit-Goâve & 429 & 75 \\
\hline \multirow{2}{*}{ Gender } & Male & 185 & 52 & Male & 257 & 45 \\
\hline & Female & 166 & 46 & Female & 291 & 51 \\
\hline \multirow{4}{*}{ Age } & $9-11$ & 159 & 44 & $11-13$ & 57 & 10 \\
\hline & $12-14$ & 119 & 33 & $13-15$ & 145 & 25 \\
\hline & $15-17$ & 45 & 13 & $15-18$ & 222 & 39 \\
\hline & $>17$ & 2 & 1 & $>18$ & 94 & 16 \\
\hline \multirow{2}{*}{ Settlement } & House & 219 & 61 & House & 437 & 76 \\
\hline & Camp Tent & 125 & 35 & Camp Tent & 136 & 24 \\
\hline \multirow{3}{*}{ Household number } & $1-4$ & 104 & 29 & $1-4$ & 213 & 37 \\
\hline & $5-7$ & 125 & 35 & $5-7$ & 111 & 19 \\
\hline & $>7$ & 107 & 30 & $>7$ & 193 & 34 \\
\hline \multirow{7}{*}{ Grade } & 2 & 20 & 6 & 1 & 94 & 16 \\
\hline & 3 & 50 & 14 & 2 & 123 & 21 \\
\hline & 4 & 87 & 24 & 3 & 88 & 15 \\
\hline & 5 & 99 & 28 & 4 & 99 & 17 \\
\hline & 6 & 102 & 28 & 5 & 73 & 13 \\
\hline & & & & 6 & 73 & 13 \\
\hline & & & & 7 & 22 & 4 \\
\hline \multirow{2}{*}{ Owning a Radio } & Yes & 237 & 66 & Yes & 431 & 75 \\
\hline & No & 107 & 30 & No & 78 & 14 \\
\hline \multirow{2}{*}{ Owning a TV } & Yes & 229 & 64 & Yes & 326 & 57 \\
\hline & No & 122 & 34 & No & 191 & 33 \\
\hline
\end{tabular}

*Percentages / frequencies might not add up to $100 \%$ due to missing data.

\subsubsection{Gender}

Out of 358 primary school pupils, 52\% were boys and $46 \%$ were girls, $4 \%$ did not indicate their gender. As regards to secondary school students, $51 \%(\mathrm{~N}=573)$ were girls, while $45 \%$ were boys, and $4 \%$ did not indicate their gender. Of the teachers and professors that participated in the survey $34 \%$ $(\mathrm{N}=59)$ were female and $66 \%(\mathrm{~N}=115)$ male. This reflects the sex distribution of teachers at school level in Haiti, where the majority is male [14].

\subsubsection{Housing}

Primary school pupils indicated that they lived with five to seven people $(35 \%)$, while $37 \%$ of secondary school children reported to have a smaller family (one to four people), though still $34 \%$ reported to live in a family with more than seven members. The average was five to six members per family. Teachers' household size was between five and seven for half of the respondents $(\mathrm{N}=88)$, while $27 \%$ reported a household size of more than seven people. Twenty percent of teachers reported household sizes of less than four people $(\mathrm{N}=35)$. Approximately $35 \%$ of primary school children and 
$24 \%$ of secondary school children reported to live in a camp tent. Thirty percent of teachers / professors reported to live in camp sites; while $44 \%$ (43 people) reported to be renting a house $(\mathrm{N}=78)$ and $24 \%(\mathrm{~N}=43)$ owned a house.

\subsubsection{Assessment on Water, Sanitation Infrastructures and Waste Management}

The project schools did not have water and sanitation facilities as per standards set up by the DINEPA. 32 out of the 42 project schools were damaged or destroyed by the earthquake, 14 of which had classes in semi-permanent hangars and no sanitation facilities or emergency facilities were in place at the time of the survey. The water and sanitation infrastructural survey -which was carried out during the authors' field mission- is reported in Table 4.

Table 4. Assessment of the 42 project schools facilities.

\begin{tabular}{|c|c|c|c|c|}
\hline Type of service & Type of facilities & $\begin{array}{c}\text { Project Schools } \\
n=42(\%)\end{array}$ & $\begin{array}{c}\text { Petit-Goâve } \\
\text { n=29 (\%) }\end{array}$ & $\begin{array}{c}\text { Grand-Goâve } \\
\text { n }=13(\%) \\
\end{array}$ \\
\hline \multirow{3}{*}{$\begin{array}{l}\text { Sanitation } \\
\text { facilities }\end{array}$} & Pit latrines/urinals & $25(60)$ & $17(59)$ & $8(62)$ \\
\hline & $\mathrm{WC}+$ septic tanks & $3(7)$ & $3(10)$ & - \\
\hline & Nothing & $14(33)$ & $9(31)$ & $5(38)$ \\
\hline \multirow{4}{*}{$\begin{array}{l}\text { Hand-washing } \\
\text { facilities }\end{array}$} & At the hand-pump & $8(19)$ & $2(7)$ & $6(46)$ \\
\hline & Tap stands & $10(24)$ & $9(31)$ & $1(8)$ \\
\hline & With buckets & $6(14)$ & $2(7)$ & $4(31)$ \\
\hline & Nothing & $18(43)$ & $16(55)$ & $2(15)$ \\
\hline \multirow{3}{*}{ Water Supply } & Water supply network & $10(24)$ & $9(31)$ & $1(8)$ \\
\hline & Borehole & $8(19)$ & $2(7)$ & $6(46)$ \\
\hline & $\begin{array}{c}\text { Nothing/ private } \\
\text { vendors }\end{array}$ & $24(57)$ & $18(62)$ & $6(46)$ \\
\hline \multirow{3}{*}{$\begin{array}{l}\text { Solid Waste } \\
\text { management }\end{array}$} & Open burning & $24(57)$ & $16(55)$ & $8(62)$ \\
\hline & Buried & $4(10)$ & $2(7)$ & $2(15)$ \\
\hline & Dumped & $14(33)$ & $10(34)$ & $4(31)$ \\
\hline
\end{tabular}

\subsubsection{Sanitation Infrastructures and Use}

From the infrastructural survey, schools that had sanitation facilities had mostly $(\mathrm{N}=25,60 \%)$ simple unlined pits of about three meters depth, with no water. The average number of pit latrines per school was two; with often (18 out of 28) no segregation between girls and boys, and the environment around the latrines was filthy and ill maintained. Out of the 42 schools surveyed, there were no latrines for disabled persons and no disabled students enrolled.

Figure 4 reports the average number of children per latrine per school. It is possible to see that below the DINEPA sanitation accessibility standard line (60 male children per latrine), 14 schools have no sanitation at all (33\%), of which 9 private. Moreover, it was found that four of the project schools (9.5\%) had a ratio of above 500 students per latrine, 14 schools (33\%) between 100 and 300 students per latrine, all far below any sanitation standards provision. 
Figure 4. Sanitation Accessibility: Number of students/latrine.

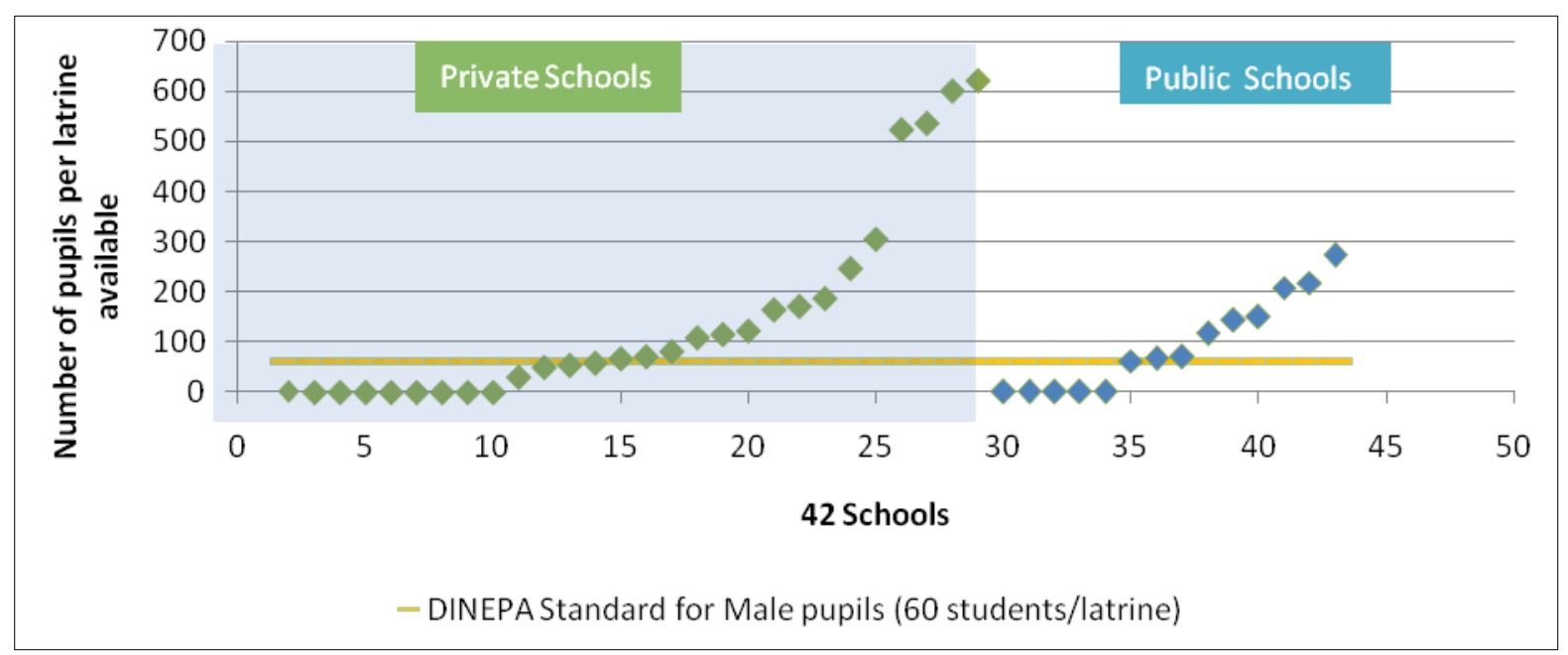

From the KAP questionnaire, pupils replied mostly to regularly use, if available, the latrines at schools (63\% primary pupils and $75 \%$ secondary pupils). However, when asked in the questionnaire what they did not like about the latrines at school, both primary pupils and secondary students complained about the lack of maintenance: Latrines were too dirty and smelly (primary $44 \%$ and secondary 56\%). For primary school children the main indication of why the latrines were not used properly was that the access was not easy. Thirty-four percent $(\mathrm{N}=123)$ reported that the latrine seat was too high and the defecation hole was considered too big (fear of falling in), resulting in a child-unfriendly design. For secondary school students, the major issue was related to lack of water for cleaning and hand-washing $(\mathrm{N}=150,26 \%)$; not enough space, and the absence of lockable doors, resulting in a lack of privacy and feeling of unsafe environment. Where septic tanks were present (only three schools) de-sludging machinery was not available in a timely way, since only three de-sludging trucks were available in Petit-Goâve. Materials for anal cleansing were not available in any of the surveyed schools. From the observational survey, where sanitation facilities did not exist at all (fourteen schools), children practiced open defecation (eight schools) or they used neighbor's latrines (six schools).

\subsubsection{Water Supply and Point of Use Treatment}

As reported in Table 4, out of the 42 schools surveyed only eight schools had private access to water supply facilities. There were two main types of water supply facilities found; these included eight shallow boreholes (two in Petit-Goâve and six in Grand- Goâve) equipped with India mark II hand pumps (15-35 meters in depth) and 10 water tap stands (eight in Petit-Goâve and two in Grand-Goâve) connected to gravity fed systems supplied by protected sources. Some $(\mathrm{N}=9,21.4 \%)$ schools reported point-of-use treatment with chlorine tablets (seven in Petit-Goâve and two in Grand-Goâve). In the schools where no water supply was available, children bought treated water at kiosks in small sachets, or bottled water, $40 \%(\mathrm{~N}=142)$ primary school children and $64 \%$ secondary students $(\mathrm{N}=366)$. As a consequence, water was not accessible to each child every day. 


\subsubsection{Solid Waste Management at Schools}

Class dustbins were only available in $14.2 \%(\mathrm{~N}=6)$ of the project schools at the observational check. No appropriate equipment and facilities were available for the collection and transportation of solid waste, resulting in a contaminated environment. Solid waste practices involved either open garbage burning every week - $57 \%$ of the project schools — or just a dump next to the school buildings or latrines. Ten percent of the project schools had an unlined refuse pit and consequently shallow water resources were not protected. Thirty-three percent of schools paid private waste collectors to dump the solid waste away from the school.

\subsubsection{Hand-Washing and Hygiene Education}

Where a water connection was not available on site, hand-washing facilities consisted of buckets with taps or a hand-pump (as reported in Table 4). Despite the fact that hand-pumps in the schools were easily accessible, there was no water available at the latrine entrance/exit, thus hand-washing might not being done at the critical times. Out of the 42 schools surveyed, only $25 \%$ had soap available, while for the rest either did not have any hand-washing facilities (almost half of the project schools), or soap was not present during the observational survey. When asked whether there was a hand-washing point at the school and whether soap was available, replies were not consistent with what was found during the observational survey. In the replies they over reported the presence of soap and presence of hand-washing points. There might be a number of reasons for this: Washing hands at a nearby place was still perceived as being in the school area, or respondents had knowledge about hand-washing with soap and wanted to show it, but they did not have the required access and resources ( $\mathrm{N}=240,67 \%$ for primary schools; $\mathrm{N}=402,70 \%$ for secondary schools). As reported by the teachers in the questionnaire, hygiene education was often not taught at school level, because classes were too crowded (with peaks of 70 pupils) and there were not enough teachers available (Table 2). As per the questionnaires, $30 \%$ of teachers declared that they spoke about hygiene during classes, mainly with the aid of posters (43\%), songs (40\%), and drawings (17\%). Moreover, some teachers declared during the interviews that although they might teach some basic hygienic behavior, if facilities were not present at the schools as well as at their home, pupils were not likely to retain them as a habit.

\subsubsection{Adequate Hygiene Knowledge}

Primary and secondary school pupils scored adequate hygiene knowledge for $68 \%$ of the respondents. When tested if adequate knowledge was related to the type of accommodation, those students with adequate knowledge of proper hygiene were more likely to live in a proper house, indicating for secondary school pupils (OR 1.86, CI 1.2-2.8) a better socio-economic condition or better coping mechanisms after the earthquake. As shown in Table 5, the percentage of primary students with adequate knowledge of proper hygiene living in a house was higher $(66.1 \% \mathrm{~N}=160)$ than those living in an Internally Displaced Camps (33.2\%), though the association did not reach statistical significance (OR 1.42, CI 0.88-2.28). Associations of knowledge and hygiene with gender were not evident. Performing analysis considering the two different cities did not provide any statistically significant difference. 
Table 5. Adequate Hygiene Knowledge in primary and secondary school pupils according to gender and housing.

\begin{tabular}{|c|c|c|c|c|c|c|}
\hline & & \multicolumn{2}{|c|}{$(\mathrm{N}$ total $=\mathbf{5 7 3})$} & \multicolumn{2}{|c|}{$\begin{array}{c}\text { Adequate Hygiene } \\
\text { Knowledge } \\
\end{array}$} & \multirow[t]{2}{*}{$\begin{array}{c}\text { Odds Ratio (MLE) } \\
(95 \% \mathrm{CI}) \\
\end{array}$} \\
\hline \multicolumn{2}{|c|}{ Secondary School Pupils } & $\mathbf{n}$ & $\%$ & $\mathbf{n}$ & $\%$ & \\
\hline \multirow{2}{*}{ Gender } & Female & 257 & 44.8 & 202 & 52.2 & $0.8835(0.6096-1.2783)$ \\
\hline & Male & 291 & 50.7 & 185 & 47.8 & 1.00 (Reference) \\
\hline \multirow{2}{*}{$\begin{array}{l}\text { Type of } \\
\text { housing }\end{array}$} & House & 437 & 76.2 & 318 & 82.8 & $1.8602(1.2039-2.8636)$ \\
\hline & Camp & 136 & 23.7 & 66 & 17.2 & 1.00 (Reference) \\
\hline \multicolumn{2}{|c|}{ Primary School Pupils } & \multicolumn{2}{|c|}{$(\mathrm{N}$ total $=\mathbf{3 5 8})$} & & & \\
\hline \multirow{2}{*}{ Gender } & Female & 166 & 46.4 & 108 & 44.3 & 1.00 (Reference) \\
\hline & Male & 185 & 51.7 & 136 & 55.7 & $0.6717(0.4241-1.0609)$ \\
\hline \multirow{2}{*}{$\begin{array}{l}\text { Type of } \\
\text { housing }\end{array}$} & House & 219 & 61.1 & 160 & 66.1 & $1.4206(0.8807-2.2858)$ \\
\hline & Camp & 125 & 34.9 & 82 & 33.9 & 1.00 (Reference) \\
\hline
\end{tabular}

*Frequencies / percentages may not add up to the total number due to missing data.

\subsubsection{Cholera Knowledge and Prevention}

The survey was conducted in late November, 2010 and cholera started spreading in late October, 2010, after one month of communication and prevention campaigns carried out by CESVI hygiene promoters to teachers and professors. A high percentage of the respondents replied to have heard about cholera: Almost all the teachers and professors $(\mathrm{N}=167)$ and $89 \%$ of secondary school pupils $(\mathrm{N}=509)$ and $72 \%(\mathrm{~N}=258)$ of primary school children. When asked what the main source of information was, primary and secondary school children reported to have heard about cholera from teachers and professors. Listening to the radio was also reported as one of the main sources of information about cholera (Figure 5). Moreover, $94 \%(\mathrm{~N}=166)$ of teachers could indicate at least two methods to prevent the disease, while $77 \%(\mathrm{~N}=439)$ of secondary school children and $68 \%(\mathrm{~N}=244)$ of primary school children could do so.

Figure 5. Response to the question "What was your source of information about cholera?".

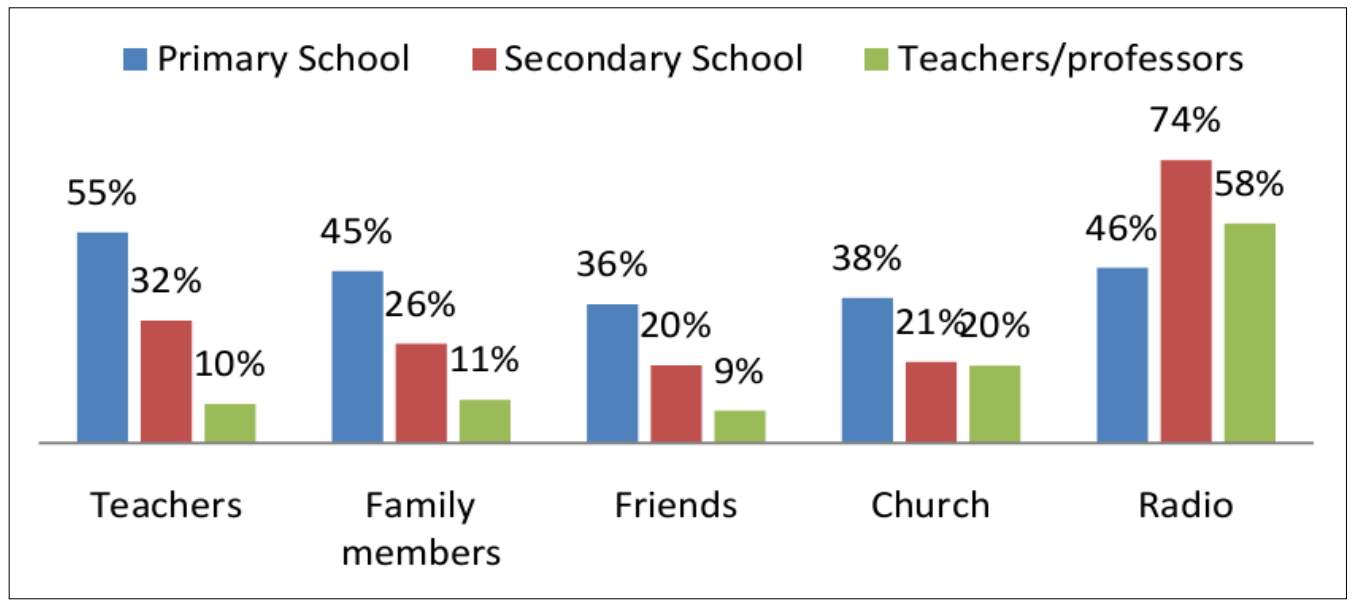

*Percentages do not add up, because multiple replies were admissible. 


\subsection{Semi-Structured Interviews with Stakeholders}

The identified stakeholder groups were divided into three categories: primary, secondary and key stakeholders. Primary stakeholders were the category of stakeholders who were directly affected by the project and who could also be referred to as the direct beneficiaries of the project. The involvement, participation and contribution of primary stakeholders in the planning and implementation of the project activities were critical, especially for the purposes of ownership and sustainability. These were the students and the teachers of the targeted schools, along with their families. Additionally, this category included the directors of the same schools and two local inspectors at the primary and secondary level. The semi-structured interviews with the directors highlighted that major losses in terms of school materials such as blackboards, books, desks and chairs had occurred with the earthquake and that some of the existing water and sanitation facilities were destroyed or damaged (32 out of the 42 project schools). Moreover, they reported that the school budget was not sufficient to construct and maintain water and sanitation facilities. Paying for a water connection bill, a cleaner and a de-sludging truck, among other operational costs, went far beyond the annual school budget. This was reported by private schools as well. Public schools did not have enough teachers and professors to fulfill the needs of scholars. As mentioned previously, hygiene training was not included in the normal curriculum and it was the personal choice of professors to dedicate some time per week during their normal teaching activities. Secondary stakeholders included the implementing and institutional partners, such as municipality members and civil protection units, which could also effectively contribute to the project implementation. The Ministry of National Education and Vocational Training (MENFP) was a key stakeholder that could offer support by creating an enabling environment for schools to pursue their mission. Other key stakeholders were donors, particularly UNICEF, and other donor agencies that could contribute to supporting MENFP in terms of policies and implementing projects. Based on the interviews, a SWOT analysis was carried out in order to highlight the challenges and opportunities of the primary stakeholders for the implementation of the project. The results are reported in Table 6. As reported in the SWOT analysis, the success of implementing a sustainable program is strongly linked to active participation from all stakeholders, including secondary stakeholders and donors. Regular monitoring and evaluation will allow identifying factors that need to be strengthened or modified to ensure a positive impact of the project.

\section{Discussions and Further Remarks}

In Haiti before the January 12, 2010 earthquake, schools were nonetheless in a precarious state, and did not meet international standards in terms of appropriate water and sanitation facilities and their use. Furthermore, the majority of schools lacked safe drinking water, sanitation and hand washing facilities, and those, which had such basic facilities, did not invest in instruction for hygiene promotion and health education [16]. Thirty-two of the 42 schools of the project had their facilities destroyed or damaged by the earthquake. Through the efforts of NGOs, UN agencies and the local community, the attendance rate of primary school children had increased by $22 \%$ by the end of 2012 [6]. 
Table 6. SWOT Analysis of primary stakeholders (Source: Authors).

\begin{tabular}{|c|c|c|c|c|}
\hline $\begin{array}{c}\text { Primary } \\
\text { Stake-Holders }\end{array}$ & Strengths & Weaknesses & Opportunities & Threats \\
\hline $\begin{array}{l}\text { School } \\
\text { Personnel }\end{array}$ & $\begin{array}{l}\text {-School directors and teachers are } \\
\text { committed to improve the school } \\
\text { environment } \\
\text {-Commitment in educating and } \\
\text { supporting children }\end{array}$ & $\begin{array}{l}\text {-Facing post disaster trauma } \\
\text {-Not paid during emergency phase up } \\
\text { to April } 2010 \\
\text {-Not enough budget for public schools } \\
\text { to pay all teachers } \\
\text {-No specific training on hygiene issues } \\
\text {-No maintenance of sanitary facilities }\end{array}$ & $\begin{array}{l}\text {-The authorizations of } \\
\text { inspectors is needed in order to } \\
\text { successfully implement project } \\
\text {-The involvement of school } \\
\text { personnel will support giving } \\
\text { continuity to the project } \\
\text {-Reaching a considerable } \\
\text { number of children with } \\
\text { hygiene campaigns }\end{array}$ & \multirow{3}{*}{$\begin{array}{l}\text {-Changes in administration and } \\
\text { leadership could cause } \\
\text { confusion in terms of roles and } \\
\text { responsibilities } \\
\text {-Lack of salary payment could } \\
\text { cause teachers to drop out } \\
\text {-Concerns about possible } \\
\text { increased work-load } \\
\text {-Cholera outbreak is } \\
\text { threatening the whole country, } \\
\text { children being at the highest } \\
\text { risk } \\
\text {-In case of natural disasters: } \\
\text { schools could close and again } \\
\text { become hosting places for } \\
\text { displaced people }\end{array}$} \\
\hline $\begin{array}{l}\text { School } \\
\text { Students }\end{array}$ & $\begin{array}{l}\text {-Link with their households and } \\
\text { their fellow colleagues for } \\
\text { learning activities }\end{array}$ & $\begin{array}{l}\text {-Facing post disaster trauma } \\
\text {-School closed from } 13 \text { January till } \\
\text { April } 2010 \\
\text {-Lower number of student inscription } \\
\text { due to relocation or other earthquake } \\
\text { effects } \\
\text {-High rate of absenteeism due to } \\
\text { difficulties in paying school fees and } \\
\text { uniforms }\end{array}$ & $\begin{array}{l}\text {-Contribute to the design and } \\
\text { maintenance of school facilities } \\
\text {-Contribute to the sanitary } \\
\text { facilities development of the } \\
\text { community where the school is } \\
\text { located } \\
\text {-Cholera sensitization could } \\
\text { reach more children than } \\
\text { conventional hygiene programs }\end{array}$ & \\
\hline Community & $\begin{array}{l}\text {-Recognize the value of the } \\
\text { institution } \\
\text {-Periodic parent meeting (not in } \\
\text { all project schools) }\end{array}$ & $\begin{array}{l}\text {-Facing post disaster trauma } \\
\text {-Not much community involvement }\end{array}$ & $\begin{array}{l}\text {-Replication factors. Do at } \\
\text { home what you do at school }\end{array}$ & \\
\hline
\end{tabular}


After the earthquake, the Direction National d'Eau et Assainissement (National Directorate of Potable Water and Sanitation, DINEPA), the Ministry of National Education (MEN) and UNICEF suggested minimum standards on water and sanitation in schools for the Haitian situation [16] that are extracted and summarized in the following Table (Table 7).

Table 7. Minimum water \& sanitation standards at school [16].

\begin{tabular}{l|l|l}
\hline \multicolumn{1}{c|}{ Sanitation } & \multicolumn{1}{c|}{ Water quantity/quality } & \multicolumn{1}{c}{$\begin{array}{c}\text { Products that have to be available } \\
\text { at the school }\end{array}$} \\
\hline $\begin{array}{l}1 \text { latrine/every } 30 \text { girls } \\
1 \text { latrine/every } 60 \text { boys }\end{array}$ & $1-1.51$ drinking water/pupil/day \\
$\begin{array}{l}\text { (1 Urinal for boys) } \\
1 \text { latrine/every } 20 \text { employees } \\
\begin{array}{l}\text { Minimum } 3 \text { latrines (low number } \\
\text { of inscriptions) }\end{array}\end{array}$ & $\begin{array}{l}\text { Water quality }(0-10 \mathrm{CF} / 100 \mathrm{ml}) \\
\text { Disinfectants products } \\
\text { Soap } \\
\text { Toilet paper } \\
1 \text { dust bin per class } \\
\text { Hand-washing near to the toilets }\end{array}$ \\
\hline
\end{tabular}

Since Haiti is threatened by several types of natural disasters (hurricanes, flooding, earthquakes, etc.), a disaster risk reduction and preparedness plan should be developed for the schools in order to be able to support students and displaced people. Schools in vulnerable areas should prepare a plan based on the emergency scenario that might occur by defining baseline data on number of pupils and teachers. The baseline would help in determining the supplies needed for possibly establishing temporary learning spaces for children. Moreover, a contingency stock with tents, tarpaulins and chlorine should be included into the school water and sanitation plan. Many schools were used to host displaced people in the aftermath of the earthquake, causing delays in the re-commencement of normal educational activities and overload of existing facilities. Additional water and sanitation facilities should be available in order to avoid overloading and sustain the re-commencement of school activities. With the cholera outbreak, further attention has been drawn to the quality of drinking water, safe storage and consumption, and to safe disposal of excrements. Fear regarding the spread of cholera started to introduce a new perception about the importance of hygiene among Haitians. Protecting children against cholera may not only decrease the burden in the children, but also decrease transmission of the disease to their family members and the community [17]. Specific materials for training and key messages for hygienic practices have been developed and disseminated by several organizations and by CESVI to the project schools. Through the KAP survey, it was possible to highlight that cholera knowledge, after only one month of hygiene communication and prevention campaigns, reached a high number of people and that the use of radio programs was deemed as the most widespread communication means. As of January, 2012 only one case of suspected cholera was found in one of the project schools (CESVI staff personal communication June 2012), while it had already hit the two nearby towns of Petit and Grand- Goâve.

After the 2010 earthquake, a high number of children were injured, many with lasting physical disabilities. According to the Ministry of Social Affairs and Labor there were only 23 schools in the whole country that accepted physically disabled persons and that have adapted facilities [18], and the surveyed schools were not among them. This highlights a potential gap in school education reaching handicapped victims and further highlights the need for schools to incorporate facilities adapted to local needs of the population. 
From the field survey carried out in Haiti and from the results of the questionnaires, a number of practical recommendations have been formulated in order to support the implementation of water, sanitation and hygiene project in Petit-Goâve and Grand-Goâve. Suggestions on how to improve the current project are also proposed in the following sections.

\subsection{Sanitation and Hygiene Promotion}

The results of the KAP questionnaires that were developed locally were used in order to establish a baseline survey for school children (both primary and secondary schools) and professors, and better address the key messages of hygiene promotion. Targeting schools can stimulate hygiene and sanitation practices which are sustained beyond the period of an intervention $[11,12,17,19]$. An alternative approach could be used and/or trialed for schools in the rural sections of Petit-Goâve and Grand Goâve, such as the community lead total sanitation and school lead total sanitation programs that have proven to be successful for schools in Nepal [20]. This approach can actively promote the participation of children and the community in order to have a safer learning environment. At least one latrine per school should be accessible to disabled children, the number of which has increased as a result of the earthquake. This will also entice the disabled to go to school. On-site sanitation technologies - ventilated simple pit latrines and urinals - have been adapted, standardized and approved by MEN and DINEPA. The school budget was not sufficient to invest in the construction of the required facilities and will also not be enough to maintain them: An operation and maintenance action plan had to be developed together with school directors and teachers to avoid abandoned facilities. The lack of separate and safe sanitary facilities for girls could be a factor to discourage girls to go to schools and contribute to their drop out, especially for adolescents. Adolescent girls found it difficult to attend schools that had no, or few, badly maintained facilities. Thus it is essential to have separate toilet facilities for girls and boys. Where sanitation facilities were connected to water supply, a method to treat or recover wastewater and sludge could be investigated. No treatment facilities were available for sludge disposal in the region. A major concern was land ownership and difficulty for the Municipality to find an appropriate space for waste disposal. Several NGOs started to advocate to the Municipality to identify such areas (also for solid waste), but this sensitive task took almost two years until suitable land was identified and two liquid waste ponds built. Another important issue was to avoid environmental pollution through the careful choices of the technology used. Simple pit latrines could overflow if exposed to flooding or heavy rainfall, causing the contamination of the superficial aquifer. To avoid the contamination of surface water, a technology that could be employed is raised toilets with sealed tanks. According to the different child age groups, varying heights of toilets seats should be previewed and taken into account in the design phase, as well as for the hand washing facility (for example not too high) for its ease of use. Moreover, lockable doors should be previewed, and enough light should be ensured inside the cubicles.

\subsection{Access to Safe and Enough Water}

Rainwater harvesting is a low cost solution that could be studied and applied more in this area. Yearly rainfall in the region has a range that varies between 1200-2700 millimeters/year [21] and two rainy seasons (March-June and August-October) are defined. Providing the connection to the water 
supply network might pose future challenges to the sustainability of the system: School budgets have to be clearly analyzed in order to allow an allocation of a monthly water fee. Moreover, water from the main water supply system was not of a suitable quality for direct drinking purposes, so a point-of-use treatment with chlorine tablets or sand filters might be suggested and school personnel trained in their use.

\subsection{Solid Waste Management}

Refuse pits for organic compostable materials could be constructed to diminish the fraction that needs to be disposed, and they could also be used as learning activity for students. In order to increase the school budget, separate collection of plastic bottles, cans, and glass bottle materials could be proposed at school level, and then sold to enterprises that manage the recycling in the capital Port-au-Prince. In order to reduce the filling rate of pits, solid waste and non-biodegradable material used for anal cleansing and menstrual hygiene should be collected separately in a container with a cover.

\section{Conclusions}

Integrated need assessments should be used even in a post-emergency phase to better address future project actions. In this case, the assessment was conducted during the implementation of a WASH-in school project to try and develop a strategy that links emergency needs to a durable and sustainable recovery phase. By conducting a detailed assessment of the schools' service infrastructures and the perceptions of students and professors, a series of recommendations have been provided to support further project implementation towards more sustainable results that could be implemented in other vulnerable areas experiencing similar situations.

After a disaster, schools should be able to accommodate displaced people and at the same time provide a safe learning space for children. This can be achieved through disaster risk preparedness plans, equipping schools with hygiene stocks and additional facilities.

However, investments alone in the provision of water and sanitation facilities do not solve the public health issues; thus underlining the cost effectiveness of integrating software components, such as a hygiene program, in order to have a long-term positive impact on school children health and on their households.

\section{Acknowledgments}

Daniela Giardina is a fellow in "Appropriate Methodologies and Techniques for International Development Cooperation" of the University of Brescia, supported by the Alberto Archetti Fund, that graduated in March 2012. The authors would like to extend thanks to CESVI who supported the field work in Petit-Goâve and Grand-Goâve, West Department, Haiti.

The development of the study and analyses of the data was performed by Daniela Giardina, with the technical support of Fausta Prandini and the supervision of Sabrina Sorlini.

Thanks to the anonymous reviewers that helped us to improve the study article.

\section{Conflicts of Interest}

The authors declare no conflict of interest. 


\section{References and Notes}

1. United Nations. A new global partnership: Eradicate poverty and transform economies through sustainable development. Available online: http://www.un.org/sg/management/pdf/HLP_P2015_ Report.pdf (accessed on 15 May 2013).

2. INEE. Minimum Standards for Education in Emergencies, Chronic Crises and Early Reconstruction. Available online: http://www.unicef.org/violencestudy/pdf/min_standards_ education_emergencies.pdf (accessed on 23 January 2012).

3. The Sphere Project. Humanitarian charter and minimum standards in disaster. Available online: http://www.sphereproject.org/content/view/720/200/lang,english/ (accessed on 23 June 2011).

4. UNICEF. Water, Sanitation and Hygiene for Schoolchildren in Emergencies: A guidebook for teachers. Available online: http://www.unicef.org/wash/files/WASH_in_Schools_in_Emergencies _Guidebook_for_teachers_.pdf (accessed on 12 May 2013).

5. Emergency Events Database (EM-DAT). The OFDA/CRED International Disaster Database. Available online: http:/www.emdat.be/ (accessed on 30 July 2011).

6. Institut Haïtien de 1'Enfance (IHE); MEASURE DHS, ICF International. EMMUS-V, Enquête Mortalité, Morbidité et Utilisation des Services. Rapport Préliminaire (in French). Available online: http://www.mspp.gouv.ht/site/downloads/Rapport\%20preliminaire\%20final\%20EMMUS-V.pdf (accessed on 7 January 2013).

7. UNICEF. Children of Haiti. Progress, Gaps and Plans in Humanitarian Action Supporting a Transformative Agenda for Children. Available online: http://www.unicef.gr/pdfs/UNICEF_ Haiti_three_month_report.pdf (accessed on 6 July 2012).

8. United Nations Office for the Coordination of Humanitarian Affairs (OCHA). Haiti Cholera snapshot. Available online: http://reliefweb.int/sites/reliefweb.int/files/resources/hti_cholera Snapshot_1\%20August\%202013.pdf (accessed on 5 August 2013).

9. Descombe, M. The Good Research Guide for Small-Scale Social Research Projects, 3rd ed.; Open University Press: Maidenhead, UK, 2007.

10. Maxwell, J.A. Qualitative Research Design: An Interactive Approach (Applied Social Research Methods Series); Sage: London, UK, 2010; Volume 41.

11. World Health Organization. Water, Sanitation and Hygiene Standards for Schools in Low-Cost Settings; Adams, J., Bartram, J., Chartier, Y., Sims, Y., Eds.; WHO: Genève, Switzerland, 2009.

12. International Water and Sanitation Centre (IRC). Towards Effective Programming for WASH in Schools; IRC: Delft, The Netherlands, 2007.

13. Haiti Education Cluster. Draft Cholera response strategy. Port-au-Prince, Haiti, November 2010. Unpublished document.

14. Salmi, J. Equity and quality in private education: The Haitian paradox. Compare 2000, 30, 163-178.

15. UN data. Haiti Country Profile. Available online: http://data.un.org/CountryProfile.aspx?cr Name=Haiti (accessed on 7 February 2011).

16. Direction Nationale de l'Eau Potable et de l'Assainissement (DINEPA). Draft, Note d'orientation sur l'eau et l'assainissement dans les établissements scolaires (in French). Available online: http://www.dinepa.gouv.ht/wash_cluster/index.php?option=com_rokdownloads\&view=file\&Item $\mathrm{id}=27 \& \mathrm{id}=1027$ :orientations-wash-ecoles (accessed on 2 September 2012). 
17. Bolt, E.; Shordt, K.; Krukkert, I. School Sanitation and Hygiene Education Results from the Assessment of a 6-Country Pilot Project; UNICEF and IRC International Water and Sanitation Centre: Delft, The Netherlands, 2006. Available online: http://www.irc.nl/page/29459 (accessed on 31 July 2011).

18. Ministère des affaires sociales et du travail (MAST), Bureau du Secrétaire d'Etat à l'intégration des personnes handicapées. Pour une Scolarisation massive des personnes handicapées (in French). Available online: http://haiti.humanitarianresponse.info/system/files/documents/files/Guidance\% 20note\%20on\%20School\%20Enrolment\%20of\%20Disabled\%20Children\%20(in\%20French).pdf (accessed on 13 March 2012).

19. Deen, J.L.; von Seidlin, L.; Sur, D.; Agtini, M.; Lucas, M.E.S.; Lopez, A.L.; Kim, D.R.; Ali, M.; Clemens, J.D. The high burden of cholera in children: Comparison of incidence from endemic areas in Asia and Africa. PLoS Negl. Trop. Dis. 2008, 10.1371/journal.pntd.0000173.

20. Bell, B. Analysis of school-led total sanitation in Chitwan, Nepal. Master's Thesis, Utrecht University, Utrecht, The Netherlands, 2010.

21. Water Resources Assessment of Haiti. Available online: http://www.gvsu.edu/cms3/assets/ 53940C9B-B252-5B69-626B48622A4C1002/publishedliterature/acoe_water_resources_of_haiti.pdf (accessed on 13 March 2012).

Appendix 1. List of Schools Assessed.

\begin{tabular}{|c|c|c|c|c|}
\hline ID & School Name & Village & Statute & $\operatorname{Level}(P$, F1, F2, S) \\
\hline 1 & Ecole N.le Mixte de Grand-Goâve & GG & Public & F1 \\
\hline 2 & Lycee Fito Gracia de Grand Goâve & GG & Public & $\mathrm{F} 2, \mathrm{~S}$ \\
\hline 3 & Ecole N.le des Filles de Grand-Goâve & GG & Public & F1 \\
\hline 4 & Ecole N.le de Thozin & GG & Public & F1 \\
\hline 5 & Centre d'Etude Secondaire Ernest Vaval & GG & Private & $\mathrm{F} 2, \mathrm{~S}$ \\
\hline 6 & Ecole Baptiste Siloe & GG & Private & $\mathrm{F} 1, \mathrm{~F} 2, \mathrm{~S}$ \\
\hline 7 & Centre Saint François d'Assise & GG & Private & $\mathrm{P}, \mathrm{F} 1-\mathrm{F} 2, \mathrm{~S}$ \\
\hline 8 & College Baptiste Maranatha & GG & Private & $\mathrm{F} 1$ \\
\hline 9 & College Chretien & GG & Private & $\mathrm{P} 2, \mathrm{~S}$ \\
\hline 10 & College Les frères Milord & GG & Private & $\mathrm{F} 2, \mathrm{~S}$ \\
\hline 11 & Ecole Batisseur de l'Espoir & GG & Private & $\mathrm{P}, \mathrm{F} 1$ \\
\hline 12 & Petit College de Grand Goâve & GG & Private & $\mathrm{F} 2, \mathrm{~S}$ \\
\hline 13 & Ecole Batisseur de l'Espoir- Colbert & GG & Private & $\mathrm{P}, \mathrm{F} 1$ \\
\hline 14 & Collège Adelina & $\mathrm{PG}$ & Private & $\mathrm{S}$ \\
\hline 15 & Collège Paul Lochard & $\mathrm{PG}$ & Private & $\mathrm{F}-\mathrm{S}$ \\
\hline 16 & Collège Phillipe Guerrier & $\mathrm{PG}$ & Private & $\mathrm{F} 1-\mathrm{F} 2, \mathrm{~S}$ \\
\hline 17 & Ecole Mixte Therese Jean & $\mathrm{PG}$ & Private & $\mathrm{P}, \mathrm{F}$ \\
\hline 18 & Collège Pierre Baptiste & $\mathrm{PG}$ & Private & $\mathrm{F}, \mathrm{S}$ \\
\hline 19 & Ecole Apostolique & $\mathrm{PG}$ & Private & $\mathrm{F}, \mathrm{S}$ \\
\hline 20 & Ecole Louis Borno & $\mathrm{PG}$ & Private & $\mathrm{F}, \mathrm{S}$ \\
\hline 21 & Lycee Faustin Soulouque & $\mathrm{PG}$ & Private & $\mathrm{F} 2, \mathrm{~S}$ \\
\hline 22 & College Harry Brakeman & $\mathrm{PG}$ & Private & $\mathrm{P}, \mathrm{F} 1-\mathrm{F} 2, \mathrm{~S}$ \\
\hline 23 & Ecole Pierre Mendès France & $\mathrm{PG}$ & Private & $\mathrm{P}, \mathrm{F} 1, \mathrm{~F} 2-\mathrm{S}$ \\
\hline
\end{tabular}


Appendix1. Cont.

\begin{tabular}{l|l|l|l|l}
\hline ID & School Name & Village & Statute & Level(P, F1, F2, S) \\
\hline 24 & Ecole Wesleyenne & PG & Private & P, F1-F2, S \\
\hline 25 & College Emilie Nau & PG & Private & S \\
\hline 26 & College Isaac Berde & PG & Private & S \\
\hline 27 & College Jean Rene Jerome & PG & Private & S \\
\hline 28 & College Notre Dame de Petit Goâve & PG & Private & S \\
\hline 29 & Ecole Yves R.Lamartine & PG & Private & P,F1 \\
\hline 30 & Institution Mixte le Renouveau & PG & Private & S \\
\hline 32 & Collège Pradel Pompilus & PG & Private & F2, S \\
\hline 33 & Ecole Adler Alexandre Leandre & PG & Private & F1 \\
\hline 34 & Ecole Nationale Gilbert Desroches & PG & Public & F1 \\
\hline 35 & Ecole de Vialet & PG & Public & P, F1 \\
\hline 37 & Lycee Roseline Vaval de Vialet & PG & Public & S \\
\hline 38 & College le Nouveau Monde & PG & Public & S \\
\hline 39 & Ecole de Tapion & PG & Public & F1-F2, S \\
\hline 40 & Ecole N.le Borno Lamarre & PG & Public & F1 \\
\hline 41 & Ecole N.le des Filles de Petit-Goâve & PG & Public & F1 \\
\hline 42 & Ecole Profesionelle Ci-Devant & PG & Public & S \\
\hline PG & Ecole N.le du Sacré Cour & PG & Public & AM: P, F1 / PM:F1 \\
\hline
\end{tabular}

$\mathrm{PG}=$ Petit-Goave, $\mathrm{GG}=$ Grand-Goave $\mathrm{P}=$ Prescolaire, F1,F2 = Ecoles Primaire and Intermediare; $\mathrm{S}=$ Secondaire.

\section{Appendix 2}

\section{Questionnaire Sections:}

A. General Questions (Age, School Grade, Family members, House/shelter).

B. Awareness (radio/TV, teachers etc.).

C. Access to water at school.

D. Waste Management at school.

E. Sanitation and Hygiene (Access to latrines at school, Physical status of sanitation facilities, Access to washing facilities and hygiene concepts).

For teachers and professors, in section B. Awareness, specific questions have been added to assess whether or not their carry out hygiene training for pupils, and if so, which materials do they use.

(C) 2013 by the authors; licensee MDPI, Basel, Switzerland. This article is an open access article distributed under the terms and conditions of the Creative Commons Attribution license (http://creativecommons.org/licenses/by/3.0/). 